\title{
The Light of Hope in Antidepressant Strategies
}

\author{
Pierre A. Geoffroy ${ }^{1,2,3}$ \\ 'Université de Paris, NeuroDiderot, Inserm, Paris, France \\ 2Department of Psychiatry and Addictive Medicine, Assistance Publique-Hôpitaux de Paris (AP-HP), University Hospital Bichat-Claude Bernard, Paris, France \\ ${ }^{3}$ Centre des troubles du sommeil-CIRCSom and Institut des Neurosciences Cellulaires et Intégratives, CNRS-UPR 3212, Strasbourg, France
}

Light therapy (LT) is both an old and a new treatment because of major new insights and evidence that have been accumulated over last decades. LT shows efficacy as a first-line monotherapy in treating seasonal and non-seasonal depression, for both unipolar and bipolar disorders. LT can be used as an add-on/augmentation strategy and increases the response to antidepressant drugs (AD), but recent findings confirmed also the need to change practices and recommend a first-line combination treatment in order to maximize patients' response rates, as a clear superiority of the combination exist compared with antidepressants alone. LT has the advantage of being also effective in improving both sleep, alertness and circadian rhythms, which may be altered in depression, contrary to AD that target mainly mood. LT effects are dependent on the light dose (determined by light irradiance level, duration of exposure, distance and angle from the light source), light color spectrum, and on the time of day of light exposure. Further research are warranted to determine the most efficient lighting parameters to use depending on depression characteristics, as well as identifying predictive biomarkers of response and tolerability.

Key Words: Phototherapy; Light therapy; Depression; Major depressive disorder; Bipolar disorders

Received: April 19, 2020 Revised: May 11, 2020 Accepted: May 11, 2020

Corresponding author: Pierre A. Geoffroy, MD, PhD, Department of Psychiatry and Addictive Medicine, University Hospital Bichat-Claude Bernard, 46 rue Henri Huchard, 75018, Paris, France.

Tel: 33-1-40-25-82-62, E-mail: pierre.a.geoffroy@gmail.com

(a) This is an Open Access article distributed under the terms of the Creative Commons Attribution Non-Commercial License (https://creativecommons.org/licenses/bync/4.0) which permits unrestricted non-commercial use, distribution, and reproduction in any medium, provided the original work is properly cited.

\section{INTRODUCTION}

Light therapy (LT) benefited from major new insights and evidence that have been accumulated over last decades. It is time to consider LT as a first-line treatment in depression and this brief review offers a snapshot of where the actual scientific knowledge stands.

\section{BRIEF LIGHT THERAPY HISTORY OF ITS CLINICAL MOOD EFFECTS}

LT is both an old and a new treatment. Old, because LT is used since the Antiquity with sun therapies that were applied in ancient Chinese, Hindu and Egyptian medicine over 15 centuries BC [1]. New, because psychiatry benefited from a recent growing interest in LT since the publication of a case-series of patients successfully treated for seasonal affective disorder (SAD) by Rosenthal et al. [2] in 1984. Since this first documentation of LT in SAD, numerous studies have been published in seasonal depressions and several meta-analyses of randomized trials have confirmed that LT is more efficient than placebo in subjects with both unipolar depression [3] and bipolar depression [4] with seasonal patterns. Interestingly, LT appeared also efficient in non-seasonal unipolar depression $[3,5]$. LT has been assessed not only as a monotherapy, but is also commonly used as an augmentation strategy to antidepressant drugs $(\mathrm{AD})$ in non-seasonal depression, for both unipolar and bipolar disorders [6,7]. Indeed, in up to $50 \%$ to $60 \%$ of patients who did not respond to $\mathrm{AD}$ monotherapy [8], LT used as an add-on/augmentation strategy increased the response [6]. In addition, a recently published meta-analysis [9] confirmed the need to change practices and recommend a first-line combination treatment in order to maximize patients' response rates, rather than using LT as a second- or third-line augmentation strategy. This meta-analysis evidence that LT and antidepressants have no superiority among each other, when introduced as a first-line treatment in major depressive episodes (MDE) with and without seasonal pattern, and with a clear superiority of the combination of the two compared with antidepressants alone [9]. This is supporting LT use as an additional excellent first-line antidepressant strategy [9]. Moreover, LT is thus not 
only the cornerstone treatment of SAD [2], but also should be used as a first-line monotherapy or combination therapy in nonseasonal MDE. In this indication, LT appears also well tolerated in the treatment of adults with moderate to severe non-seasonal unipolar depression, with effect sizes equivalent to those observed in trials using selective serotonin reuptake inhibitors [3,5], as in bipolar disorder [10].

\section{OTHER EFFECTS OF LIGHT IN MOOD DISORDERS}

LT has the advantage of being also effective in improving both sleep and circadian rhythms, which may be altered in depression, contrary to $\mathrm{AD}$ that target mainly mood [11]. Interestingly first evidence of possible LT efficacy comes from basic neurosciences reporting in 1979 that phase shifts of circadian rhythms could have an antidepressant effect [12] and in 1980 that light suppresses melatonin secretion and so impacts circadian rhythms in humans, like for all other mammals [13]. Thus antidepressant effect of LT may be link to both a phase advance and/ or alignment of circadian rhythms, first confirmed by Kripke et al. $[14,15]$ and Lewy et al. [16], but also to more direct effects [17]. Indeed, LT effects are associated with mechanisms that are independent of the circadian clock and act directly on monoaminergic pathways, as suggested with observed efficacy even at midday $[17,18]$. These direct and indirect effects may explain why light exerts a strong direct and rapid effect on mood $[18,19]$. LT also enhances alertness with such direct and rapid effect [20] and increases the sleep homeostasis, which regulates the sleep intensity [21]. LT has also demonstrated to improve sleepiness and sustained attention [22]. This multiple possible interesting effects, depending on the clinical manifestations, are dependent on the light dose (determined by light irradiance level, duration of exposure, distance and angle from the light source), light color spectrum, and on the time of day of light exposure [23-25]. Further research are warranted to determine the most efficient lighting parameters to use [26]. Figure 1 summarizes the parameters and effects of LT in mood disorders. Table 1 summarizes the standard protocols for LT in MDE [27].

\section{PERSPECTIVES}

It remains critical to evaluate whether LT can be used as a maintenance treatment, as well as identifying predictive biomarkers of response and tolerability. In addition, light effects and tolerance may depend on depression subtypes, warranting specific further studies. Indeed, depression encompasses very heterogeneous entities such as $\mathrm{SAD}$, unipolar or bipolar subtypes, psychotic, melancholic, etc., which may benefit from different efficient lighting parameters, as in bipolar disorders where patients should be pretreated with an anti-manic mood stabilizer and light be titrated with a daily exposure time starting with 15 minutes (instead of 30 min in unipolar depression) and increased slowly to avoid manic switch [27]. Nevertheless this agenda is possible and very expected only because from a clinical level LT appears as a clear efficient antidepressant strategy that deserve his place in the first-line therapeutic armamentarium of MDE. In line with this, the International Society for Bipolar Disorders (ISBD) task force recently published

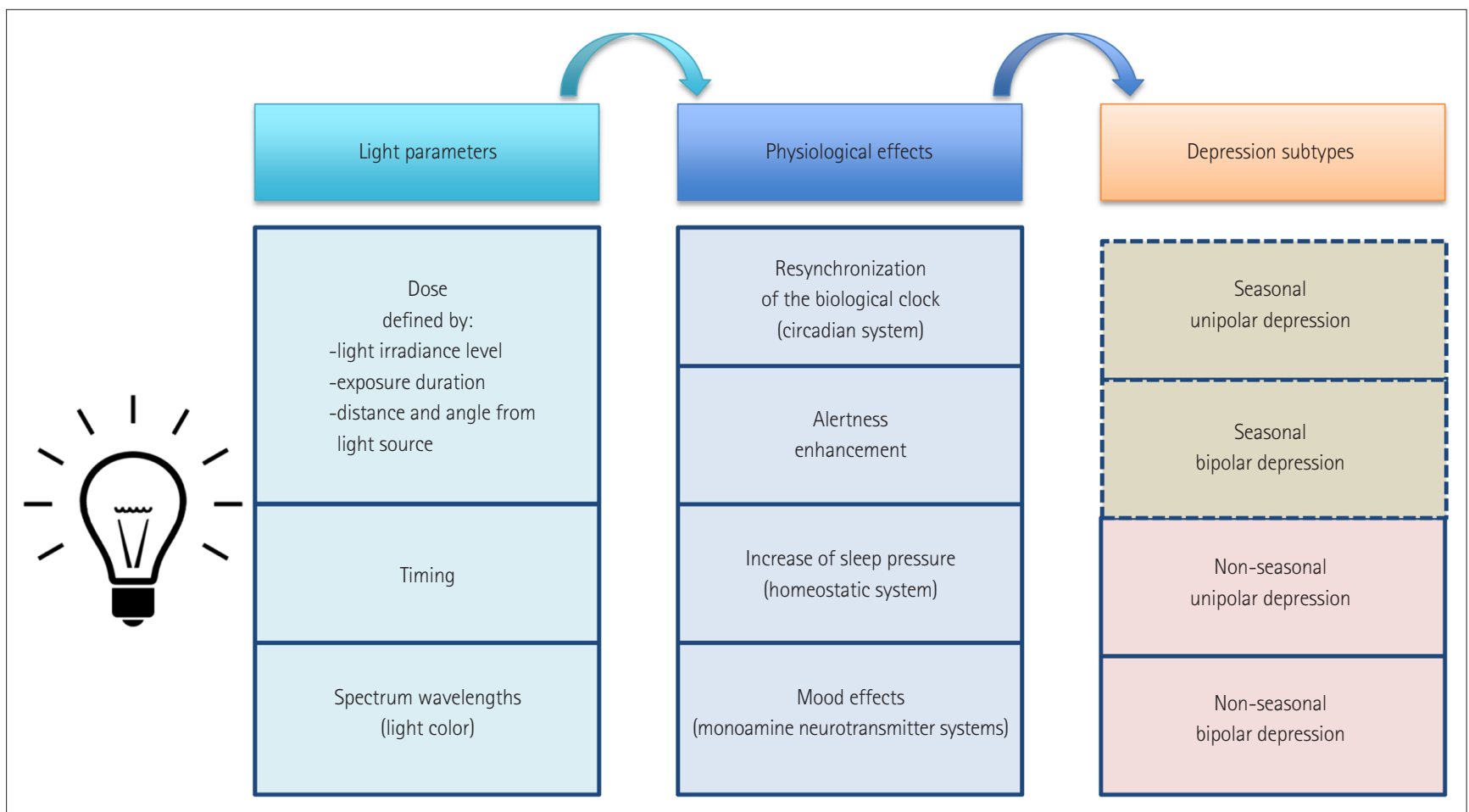

Figure 1. Parameters and effects of light therapy in mood disorders. 
Table 1. Standard protocols for light therapy in major depressive episode

\begin{tabular}{|c|c|}
\hline \multicolumn{2}{|l|}{ Dose } \\
\hline $\begin{array}{l}\text { Light irradiance level depends } \\
\text { on exposure duration }\end{array}$ & $\begin{array}{l}10,000 \text { lux for } 30 \mathrm{~min} / \text { day; or } 5,000 \text { lux for } 1 \mathrm{~h} / \text { day; or } 2,500 \text { lux for } 2 \mathrm{~h} / \text { day } \\
\text { cf) If bipolar disorders: slower increase, for instance-5,000 lux with increase of } 15 \text { min per week until } \\
60 \text { min at one month (depending on efficacy and tolerance) }\end{array}$ \\
\hline Distance and angle from light source & Lamp at eye level; distance of $30-80 \mathrm{~cm}$ (depending on the device recommendations); direct exposition \\
\hline Timing & $\begin{array}{l}\text {-Early morning (for instance: } 8 \mathrm{AM} \text {, chronotype may be considered) } \\
\text {-Daily, with regular schedules } \\
\text { cf) If bipolar disorders: consider midday (especially if there is an history of manic switch) or early morning }\end{array}$ \\
\hline Onset of response & 1 week \\
\hline Treatment duration & $\begin{array}{l}\text { Until reduction of depressive symptoms or maintained in case of relapse when stopped; or } \\
\text { If seasonal patterns: until the period of usual spontaneous remission in the spring or summer }\end{array}$ \\
\hline Prevention & Possibility to treat by light therapy a few weeks before the usual seasonal depressive relapse period \\
\hline Manic switch prevention & Only with a mood stabilizer with antimanic properties in case of bipolar disorders \\
\hline Adverse effects & $\begin{array}{l}\text { Manic switch; } \\
\text { Mild side effects: headache, eyestrain, nausea, agitation }\end{array}$ \\
\hline Contraindications & $\begin{array}{l}\text { Ophthalmic disorders (cataract, macular degeneration, glaucoma, retinitis pigmentosa) and disorders } \\
\text { affecting the retina (retinopathy, diabetes, herpes, etc.) }\end{array}$ \\
\hline
\end{tabular}

Adapted from Maruani and Geoffroy. Front Psychiatry 2019;10:85 [27].

practice recommendations for LT as a first-line treatment in bipolar depression [28].

\section{Acknowledgments}

None

\section{Conflicts of Interest}

The author has no potential conflicts of interest to disclose.

\section{ORCID iD}

Pierre A. Geoffroy (10

https://orcid.org/0000-0001-9121-209X

\section{REFERENCES}

1. Choukroun J, Geoffroy PA. Light therapy in mood disorders: a brief history with physiological insights. Chronobiol Med 2019;1:3-8.

2. Rosenthal NE, Sack DA, Gillin JC, Lewy AJ, Goodwin FK, Davenport Y, et al. Seasonal affective disorder. A description of the syndrome and preliminary findings with light therapy. Arch Gen Psychiatry 1984;41:72-80.

3. Golden RN, Gaynes BN, Ekstrom RD, Hamer RM, Jacobsen FM, Suppes T, et al. The efficacy of light therapy in the treatment of mood disorders: a review and meta-analysis of the evidence. Am J Psychiatry 2005;162:656-662.

4. Tseng PT, Chen YW, Tu KY, Chung W, Wang HY, Wu CK, et al. Light therapy in the treatment of patients with bipolar depression: a meta-analytic study. Eur Neuropsychopharmacol 2016;26:1037-1047.

5. Al-Karawi D, Jubair L. Bright light therapy for nonseasonal depression: meta-analysis of clinical trials. J Affect Disord 2016;198:64-71.

6. Penders TM, Stanciu CN, Schoemann AM, Ninan PT, Bloch R, Saeed SA. Bright light therapy as augmentation of pharmacotherapy for treatment of depression: a systematic review and meta-analysis. Prim Care Companion CNS Disord [Internet] 2016 Oct 20;18(5). Available at: https://doi.org/10.4088/ PCC.15r01906.

7. Camardese G, Leone B, Serrani R, Walstra C, Di Nicola M, Della Marca G, et al. Augmentation of light therapy in difficult-to-treat depressed patients: an open-label trial in both unipolar and bipolar patients. Neuropsychiatr Dis Treat 2015;11:2331-2338.

8. Fava M. Diagnosis and definition of treatment-resistant depression. Biol Psychiatry 2003;53:649-659.
9. Geoffroy PA, Schroder CM, Reynaud E, Bourgin P. Efficacy of light therapy versus antidepressant drugs, and of the combination versus monotherapy, in major depressive episodes: a systematic review and meta-analysis. Sleep Med Rev 2019;48:101213.

10. Benedetti F. Rate of switch from bipolar depression into mania after morning light therapy: a historical review. Psychiatry Res 2018;261:351-356.

11. Menculini G, Verdolini N, Murru A, Pacchiarotti I, Volpe U, Cervino A, et al. Depressive mood and circadian rhythms disturbances as outcomes of seasonal affective disorder treatment: A systematic review. J Affect Disord 2018;241:608-626.

12. Wehr TA, Wirz-Justice A, Goodwin FK, Duncan W, Gillin JC. Phase advance of the circadian sleep-wake cycle as an antidepressant. Science 1979;206:710-713.

13. Lewy AJ, Wehr TA, Goodwin FK, Newsome DA, Markey SP. Light suppresses melatonin secretion in humans. Science 1980;210:1267-1269.

14. Kripke DF. Photoperiodic mechanisms for depression and its treatment. In: Perris C, Struwe G, Jansson B, editors. Biological psychiatry. Amsterdam: Elsevier/ North-Holland Biomedical Press, 1981, p. 1249-1252.

15. Kripke DF, Risch SC, Janowsky D. Bright white light alleviates depression. Psychiatry Res 1983;10:105-112.

16. Lewy AJ, Kern HA, Rosenthal NE, Wehr TA. Bright artificial light treatment of a manic-depressive patient with a seasonal mood cycle. Am J Psychiatry 1982;139:1496-1498.

17. Sit DK, McGowan J, Wiltrout C, Diler RS, Dills JJ, Luther J, et al. Adjunctive bright light therapy for bipolar depression: a randomized double-blind placebo-controlled trial. Am J Psychiatry 2018;175:131-139.

18. Stephenson KM, Schroder CM, Bertschy G, Bourgin P. Complex interaction of circadian and non-circadian effects of light on mood: shedding new light on an old story. Sleep Med Rev 2012;16:445-454.

19. Huang L, Xi Y, Peng Y, Yang Y, Huang X, Fu Y, et al. A visual circuit related to habenula underlies the antidepressive effects of light therapy. Neuron 2019;102:128-142.

20. Cajochen C. Alerting effects of light. Sleep Med Rev 2007;11:453-464.

21. Tsai JW, Hannibal J, Hagiwara G, Colas D, Ruppert E, Ruby NF, et al. Melanopsin as a sleep modulator: circadian gating of the direct effects of light on sleep and altered sleep homeostasis in Opn4(-/-) mice. PLoS Biol 2009; 7:e1000125.

22. Comtet H, Geoffroy PA, Kobayashi Frisk M, Hubbard J, Robin-Choteau L, Calvel L, et al. Light therapy with boxes or glasses to counteract effects of acute sleep deprivation. Sci Rep 2019;9:18073.

23. Hubbard J, Ruppert E, Gropp CM, Bourgin P. Non-circadian direct effects of light on sleep and alertness: lessons from transgenic mouse models. Sleep Med Rev 2013;17:445-452. 
24. Bourgin P, Hubbard J. Alerting or somnogenic light: pick your color. PLoS Biol 2016;14:e2000111.

25. Wirz-Justice A, Benedetti F. Perspectives in affective disorders: clocks and sleep. Eur J Neurosci 2020;51:346-365.

26. Geoffroy PA, Schroder CM, Bourgin P. Light treatment in depression: an antique treatment with new insights. Sleep Med Rev 2018;40:218-219.
27. Maruani J, Geoffroy PA. Bright light as a personalized precision treatment of mood disorders. Front Psychiatry 2019;10:85.

28. Gottlieb JF, Benedetti F, Geoffroy PA, Henriksen TEG, Lam RW, Murray G, et al. The chronotherapeutic treatment of bipolar disorders: a systematic review and practice recommendations from the ISBD task force on chronotherapy and chronobiology. Bipolar Disord 2019;21:741-773. 